\title{
A combined targeted mutation analysis of IRF6 gene would be useful in the first screening of oral facial clefts
}

Yah-Huei Wu-Chou ${ }^{1,2,3^{*}}$, Lun-Jou Lo ${ }^{2,4,5}$, Kuo-Ting Philip Chen ${ }^{2,4}$, Chun-Shin Frank Chang ${ }^{2,3,4}$ and Yu-Ray Chen ${ }^{2,3,4}$

\begin{abstract}
Background: Interferon Regulatory Factor 6 (IRF6) is a member of the IRF family of transcription factors. It has been suggested to be an important contributor to orofacial development since mutations of the IRF6 gene has been found in Van der Woude (NWS) and popliteal pterygium syndromes (PPS), two disorders that can present with isolated cleft lip and palate. The association between IRFG gene and cleft lip and palate has also been independently replicated in many populations.
\end{abstract}

Methods: We screened a total of 155 Taiwanese patients with cleft lip with or without cleft palate (CL/P); 31 syndromic (including 19 WWS families), 44 non-syndromic families with at least two affected members, and 80 nonsyndromic patients through a combined targeted, polymerase chain reaction (PCR)-based mutation analysis for the entire coding regions of IRF6 gene.

Results: We found 11 mutations in 57.89\% (11/19) of the WWS patients and no IRF6 mutation in 44 of the nonsyndromic multiplex families and 80 non-syndromic oral cleft patients. In this IRF6 gene screening, five of these mutations (c.290 A>G, p.Tyr97Cys; c.360-375 16 bp deletion, p.Gln120HisfsX24; c.411_412 insA, p.Glu136fsX3; c.871 A>C, p.Thr291Pro; c.969 G>A, and p.Trp323X) have not been reported in the literature previously. Exon deletion was not detected in this series of IRF6 gene screening.

Conclusions: Our results confirm the crucial role of IRF6 in the WWS patients and further work is needed to explore for its function in the non-syndromic oral cleft with vary clinical features.

Keywords: IRF6 gene, Mutation analyses, Orofacial clefts

\section{Background}

Orofacial clefts are common congenital malformations which require long-term treatment and patient care. They are usually classified as either cleft lip with or without cleft palate $(\mathrm{CL} / \mathrm{P})$ or cleft palate only $(\mathrm{CP})$, based on differences in embryological development $[1,2]$. Approximately $70 \%$ of cases of orofacial clefting occur as isolated entities with no other apparent cognitive or craniofacial structural abnormalities and are commonly termed 'isolated, non-syndromic CL/P $(\mathrm{NSCL} / \mathrm{P})$ '; while many syndromic forms have simple

\footnotetext{
* Correspondence: yhwc8876@gmail.com

${ }^{1}$ Department of Medical Research, Chang Gung Memorial Hospital, No. 5,

Fushing Street, Kweishan, Taoyuan, Taiwan

${ }^{2}$ Craniofacial Research Center, Chang Gung Memorial Hospital, Linkou,

Taiwan

Full list of author information is available at the end of the article
}

Mendelian patterns of inheritance and therefore are amenable to disease gene identification [3-5]. Previous genetic and epidemiological studies have indicated that the causes of nonsyndromic CL/P are multifactorial, with both genetic and environmental factors contributing to the phenotype [6-9].

Of the large number of candidate genes thought to contribute to orofacial clefting, Interferon Regulatory Factor 6 (IRF6) is the only gene that has shown a convincing degree of consistency across studies [10,11]. Mutations in IRF6 were first identified in the autosomal dominant van der Woude syndrome (VWS; OMIM 119300), which is traditionally recognized as a monogenic syndrome characterized by lip pits, clefting of the primary or secondary palate, and hypodontia [12]. Van der Woude syndrome (VWS) is estimated as most

\section{Biomed Central}


common syndromic form of oral clefts, accounting for $2 \%$ of all cases of cleft lip and palate, and has the most closely similarities in phenotype with that of common non-syndromic forms [13-15]. Up to date, at least 200 different mutations in the IRF6 gene have been described with the majority being protein truncation mutations (nonsense and frameshifts) or missense mutations [16]. Given the overlapping phenotype of VWS with isolated $\mathrm{CL} / \mathrm{P}$, in searching the gene for mutations, nonpathogenic variants in IRF6 gene have also been found to be significantly associated with nonsyndromic oral clefting in many different populations and ethnic groups [10,17-23].

In order to determine the contribution of mutations in IRF6 to oral clefts in the Taiwanese population, we applied a combination of targeted, PCR-based experimental approaches (including polymerase chain reaction (PCR), Denature High Performance Liquid Chromatography (DHPLC), Multiplex ligation-dependent probe amplification (MLPA), TOPO cloning and DNA sequence analysis) for a cohort of oral cleft patients from Craniofacial center of Chang Gung Memorial Hospital.

\section{Methods}

\section{Study subjects}

All patients were clinically assessed by the plastic surgeon and diagnosis as $\mathrm{CL} / \mathrm{P}$ or $\mathrm{CP}$ based on clinical examination, medical records, and a detailed questionnaire through Chang Gung Craniofacial Center. A total of 155 patients with CL/P were included (31 syndromic, 44 non-syndromic families with at least two affected members, and 80 non-syndromic patients). Diagnostic criteria for individuals to be considered affected with VWS included CLP or CPO, and at least one affected individual in the family with an anomaly in the lower lip, generally bilateral pits. Cases in this series (collected from 1997-2011) were selected only from cleft patients, thus VWS patients presenting only with lower lip pits were not included. In addition to these families, a total of 100 healthy volunteers with no family history of VWS and cleft lip and/or cleft palate were recruited as a control group for genetic analysis. This study was approved by Chang Gung Medical Foundation Institutional Review Board (No. 98-2610C) and written informed consent was obtained from all patients or their parents prior to participation in this study.

\section{Molecular genetics analysis} $D N A$ extraction and $P C R$ amplification

Genomic DNA from blood were prepared from all the study subjects by standard proteinase $\mathrm{K}$ digestion and phenol/chloroform extraction using PUREGENE DNA purification kit from GENTRA (Minneapolis, Minn, USA).
The exon-intron structure and sequence for entire IRF6 gene were assessed from the National Center for Biotechnology Information (NCBI) web site and published literature. The oligonucleotide primers for amplification of each exon and adjacent splice sites and at least $40 \mathrm{bp}$ upstream of the acceptor splice sites and least $40 \mathrm{bp}$ downstream of donor sites were designed with Primer3 (http://frodo.wi.mit.edu/primer3/input. $\mathrm{htm})$. PCR amplification was performed using an automated thermocycler 9600/9700 (Applied Biosystem) in a final volume of $25 \mathrm{ul}$ containing $25 \mathrm{ng}$ of template DNA, 2.5 ul 10× reaction buffer(Sigma), 0.8 ul $25 \mathrm{mM}$ of dNTP, $5 \mathrm{ng}$ of each of the primers and 0.25 units of Taq polymerase. The amplification conditions were adjusted to the best condition for each exon and were: denaturation at $94^{\circ} \mathrm{C}$ for 2 minutes; 30 cycles each at $94^{\circ} \mathrm{C}$ for 30 seconds, $56^{\circ} \mathrm{C}$ or $60^{\circ} \mathrm{C}$ for 30 seconds, and $72^{\circ} \mathrm{C}$ for 30 seconds; and $72^{\circ} \mathrm{C}$ for 5 minutes.

\section{Mutation detection using denature high performance liquid chromatography}

PCR products were denatured and reannealed prior to DHPLC analysis using a PCR program of briefly heating to $95^{\circ} \mathrm{C}$ for $5 \mathrm{~min}$ followed by slow cooling to $25^{\circ} \mathrm{C}$ at a rate of $1^{\circ} \mathrm{C}$ every 30s. The products were then run on a WAVE-3500 Transgenomic WAVE ${ }^{\mathrm{TM}}$ machine equipped with a DNASep column and WAVE Optimized ${ }^{\mathrm{TM}}$ Buffer (Transgenomic Inc., Crewe, UK). The oven temperatures for optimal heteroduplex separation were resolved with Navigator v1.5.2 software, which gives a computerassisted determination of melting profile and analytical conditions for each fragment. Wild-type DHPLC elution profiles were characterized for each exon fragment by analyzing at least two normal control DNA samples.

\section{Dissection of genomic rearrangement for candidate genes using MLPA}

Multiplex ligation-dependent probe amplification (MLPA) was performed with $100 \mathrm{ng}$ of genomic DNA according to manufacturer's instructions using the SALSA MLPA KIT P304-A1 IRF6 (MRC-Holland, Amsterdam, the Netherlands). This MLPA assay was designed to detect deletions/duplications of one or more exons of the IRF6 gene. Probe amplification products were run on an ABI 3730 DNA Analyzer using GS500 size standard (Applied Biosystems). MLPA peak plots were visualized using Genemapper Software version 3.7 (Applied Biosystems). Non-normalized values for peak height and peak area were then exported from Genemapper Software version 3.7 to an Excel template. Normalization of data and calculation of dosage ratios were performed as described at www.mlpa.com. 


\section{TOPO TA cloning and DNA sequencing}

We performed TOPO TA cloning to distinguish allelic status of PCR products with aberrant DNA sequence. This strategy allows PCR inserts to ligate efficiently with the topoisomerase I-bound vector (Invitrogen, CA, USA). At least 10 colonies were selected and analyzed by restriction enzyme-EcoRI to confirm the presence of the insert. Finally, plasmids were further confirmed by sequencing using ABI prism 3730 automated DNA Sequencer (Applied Biosystems). Sequence was analyzed using Sequencing Analysis 5.2 software. Autoassembler computer program (Applied Biosystems) was used for sequence alignments and analysis. DNA sequence variants were confirmed by sequencing the opposite strand of the PCR product. Mutations and polymorphisms were sequenced in 96 control chromosomes from ethnically matched, unaffected individuals.

\section{Results}

We screened a total of 155 patients with CL/P; 31 syndromic, 44 non-syndromic families with at least two affected members, and 80 non-syndromic patients through a procedure of mutation analysis for the entire PCR-amplified protein coding regions of IRF6. Eleven different mutations occurring in exons $3,4,5$, and 7 of IRF6 gene were identified in the VWS patients $(11 / 19$, $57.89 \%$ ). (Table 1) None was detected in 44 of the nonsyndromic multiplex families and 80 non-syndromic oral cleft patients. Seven mutations (p.Ala16Val, p.Trp28X, p.Arg84Cys, p.Arg84His, p.Lys89Glu, p.Tyr97Cys, and p.Gln120HisfsX24) affected the DNA-binding domain, which is involved in DNA interactions. Three mutations (p.Thr291Pro, p.Trp323X, and p.Cys347Phe) were found in the Smad-interferon regulatory factor-binding domain that is critical for both homo- and hetero-dimerization of IRF6 protein. There were one mutations (p.Lys137fsX3) detected downstream of the DNA-binding domain. In the present study, all affected members were heterozygous for their respective mutation and five of these mutations (p.Tyr97Cys, p.Gln120HisfsX24, p.Glu136fsX3, p.Thr291Pro, and p.Trp323X) have not been reported in the literature previously (Additional file 1: Figure S1). We also apply the multiplex ligation-dependent probe amplification technique (MLPA) to test for single/multiple exon deletions/duplication within the IRF6 gene. However, there were no such mutations detected in this study. For those multiplex families, mutations detected in VWS-1, VWS -6, VWS -N9, and VWS-N90 are all cosegregated with their affected members in the family (data not shown).

\section{Discussion}

We have identified 11 different IRF6 mutations in VWS patients and none in 44 of the non-syndromic multiplex families and 80 non-syndromic oral cleft patients. In the present study, all affected members were heterozygous

Table 1 IRF6 mutations identified in VWS patients

\begin{tabular}{|c|c|c|c|c|c|c|c|}
\hline Pt no. & SEX & Family history & Cleft type & Exon & IRF6 mutation & aa changed & Lip pit/nodules \\
\hline WW-1 & $M$ & positive & BCLP & 7 & c. $1040 \mathrm{G}>\mathrm{T}$ & p. Cys347Phe & 2 pits \\
\hline WWS-2 & $\mathrm{F}$ & negative & BCLP & 4 & c. $265 A>G$ & p. Lys89Glu & 2 pits \\
\hline WW-3 & $\mathrm{F}$ & negative & RCLP & - & - & - & 2 asymmetric pits \\
\hline WS-4 & $\mathrm{F}$ & negative & BCLP & 5 & c. $411 \_412$ ins $A$ & p. Lys $137 f s X 3$ & 2 pits \\
\hline WW-5 & M & negative & $\mathrm{BCL}$ & $3+4$ & c. 47 C>T, c. $290 \mathrm{~A}>\mathrm{G}$ & p.Ala16Val, p.Tyr97Cys & 2 pits \\
\hline WW-6 & M & positive & BCLP & 7 & c. $969 \mathrm{G}>\mathrm{A}$ & p. Trp323X & 2 pits \\
\hline WW-7 & M & negative & RCLP & - & - & - & 2 pits \\
\hline WW-8 & $\mathrm{F}$ & negative & BCLP & 4 & c. $250 \mathrm{C}>\mathrm{T}$ & p. Arg84Cys & 2 pits \\
\hline WW-9 & $\mathrm{F}$ & negative & BCLP & 4 & c. $333 \mathrm{~T}>\mathrm{C}$ & p. Tyr111Tyr & 2 pits \\
\hline WWS-N9 & M & positive & BCLP, incomplete & 4 & C. $251 \mathrm{G}>\mathrm{A}$ & p. Arg84His & 2 pits \\
\hline WWS-11 & $\mathrm{F}$ & negative & BCLP & 4 & c. $251 \mathrm{G}>\mathrm{A}$ & p. Arg84His & 2 pits \\
\hline WWS-12 & M & negative & BCLP & - & - & - & 2 pits \\
\hline WW-N90 & $\mathrm{F}$ & positive & BCLP & 4 & c. $360-37516$ bp del & p. Gln120HisfsX24 & 2 pits \\
\hline WWS-14 & $\mathrm{F}$ & negative & $\mathrm{LCL}$ & - & - & - & 2 asymmetric pits \\
\hline WWS-15 & M & negative & $B C L P$ & - & - & - & 2 pits \\
\hline WWS-N93 & M & negative & LCLP & 3 & c. $83 \mathrm{G}>\mathrm{A}$ & p. Trp28X & 2 pits \\
\hline WS-N98 & $\mathrm{F}$ & positive & LCLP & - & - & - & 2 asymmetric pits \\
\hline old pt & M & positive & LCLP & 5 & $c .411 \mathrm{G}>\mathrm{A}$ & p. Lys137Lys & 2 pits \\
\hline 194 & M & negative & BCLP & 7 & C.871 $A>C$ & p. Thr291Pro & 2 pits \\
\hline
\end{tabular}


for their respective mutation and five of these mutations (p.Tyr97Cys, p.Gln120HisfsX24, p.Glu136fsX3, p.Thr291Pro, and p.Trp323X) have not been reported in the literature previously.

Interferon Regulatory Factor 6 (IRF6) is a member of transcription factors that contain a highly conserved helix-turn-helix DNA-binding domain and a less conserved SMAD-IRF-binding domain [12]. It has been suggested to be important contributor to orofacial development since mutations of the IRF6 gene have been found in Van der Woude (VWS) and popliteal pterygium syndromes (PPS), two disorders that can clinically resemble an isolated cleft lip and palate [12]. They were detected in approximately 70\% of VWS and $97 \%$ of PPS cases [16]. Microdeletion of 1q32-q41 is relatively rare, and only a few cases have been reported in the medical literature [24-26]. While the majority of the VWS mutations were spread over exons $3,4,7,8$ and 9 , the majority of PPS mutations were concentrated in exons 3 and 4 [16,27]. Basically, our results support a non-random distribution of IRF6 mutations in VWS. More recently, patients with nonsyndromic oral clefts have also been reported to have IRF6 mutation [27-30]. Two authors have observed IRF6 mutations among families with mixed cleft phenotype, but they were unable to exclude VWS completely $[28,29]$. Therefore, molecular differentiation between these overlapping cleft syndromes is absolutely essential before counseling can be given to family members.

The incidence of VWS among cleft patients in our population is 0.73 to 0.98 per 100,000 , which is lower than those reported from other studies [31]. The result of IRF6 mutation screening for our VWS is also low (57.89\%). All these VWS cases were selected from cleft patients, thus VWS patients presenting only with lower lip pits were not included. The patients in our series had more severe types of cleft, with a higher incidence of bilateral complete cleft lip and palate than given in other reports. The size, shape, and depth of the pits varied among patients beyond oral cleft phenotypes. The associated anomalies found in our series included hemangioma, hypertelorism, syngnathism, protruding ears, ventricular septal defect, toe and foot anomaly, and undescended testis. All the differences in the distribution of the different types of cleft, the penetrance, and familial occurrence between our study and other reports may be explained by ethnic and/or nongenetic environmental factors.

Lip and palate formations are the consequence of a complex processes that involves cell proliferation, cell differentiation, cell adhesion, and apoptosis. In theory, failure anywhere in these processes can lead to clefts $[2,32]$. We hypothesize that IRF6 may play different roles in combination with other genetic and/or environmental factors during the embryonic development [33,34]. Information regarding the profile of gene-gene or gene-environment interaction or network for the craniofacial development should also be considered. Meta analysis of mutationproved IRF6-related phenotypes might provide another useful indicator for the diagnosis of orofacial cleft in the near future.

\section{Conclusions}

This is one of the largest single reports of IRF6 mutation screens applying a combined targeted mutation analysis. Our results confirm the crucial role of IRF6 in the VWS patients and further work is needed to explore for its function in the non-syndromic oral cleft with vary clinical features.

\section{Additional file}

Additional file 1: Figure S1. The chromatograms of novel mutations in WW patients.

\section{Abbreviations}

CL/P: Cleft lip with or without cleft palate; CP: Cleft palate only; NSCL/P: Non-syndromic CL/P; WW: Van der Woude syndrome; PPS: Popliteal pterygium syndromes; PCR: Polymerase chain reaction; DHPLC: Denature high performance liquid chromatography; MLPA: Multiplex ligationdependent probe amplification.

\section{Competing interests}

The authors declare that they have no competing interests.

\section{Authors' contributions}

YHWC conceived and designed the study. The study subjects were assessed by plastic surgeons LJL, KTC, CSC, and YRC at Chang Gung Craniofacial Center. YHWC performed all the lab data analysis, interpreted the results and drafted the manuscript. All authors provide expertise and approved the final manuscript.

\section{Acknowledgements}

We thank all the participating patients and their families who made this study possible. This work was supported by the Chang Gung Medical Foundation (CMRPG381261, YHWC). The authors are also grateful to Expensive Advanced Instrument Core Laboratory, DNA Sequencing Core Laboratory and Genomic Medicine Research Core Laboratory, Chang Gung Memorial Hospital, Linkou.

\section{Author details}

'Department of Medical Research, Chang Gung Memorial Hospital, No. 5, Fushing Street, Kweishan, Taoyuan, Taiwan. ${ }^{2}$ Craniofacial Research Center Chang Gung Memorial Hospital, Linkou, Taiwan. ${ }^{3}$ Graduate Institute of Clinical Medical Science, Chang Gung University, Taoyuan, Taiwan. ${ }^{4}$ Department of Plastic and Reconstructive Surgery, Chang Gung Memorial Hospital, Linkou, Taiwan. ${ }^{5}$ Graduate Institute of Dental and Craniofacial Science, Chang Gung University, Taoyuan, Taiwan.

Received: 6 November 2012 Accepted: 13 March 2013

Published: 20 March 2013

\section{References}

1. Shprintzen RJ: Terminology and classification of facial clefting. In Understanding craniofacial anomalies: the etiopathogenesis of craniosynostosis and facial clefting. Edited by Mooney MP, Siegel MI. New York: John Wiley and Sons; 2002:17-28.

2. Marazita ML, Mooney MP: Current concepts in the embryology and genetics of cleft lip and cleft palate. Clin Plastic Surg 2004, 31:125-140. 
3. Cobourne MT: The complex genetics of cleft lip and palate. Eur J Orthodontics 2004, 26:7-16.

4. Stanier P, Moore GE: Genetics of cleft lip and palate: syndromic genes contribute to the incidence of non-syndromic clefts. Hum Mol Genet 2004, 13:R73-81.

5. Jugessur A, Murray JC: Orofacial clefting: recent insights into a complex trait. Curr Opin Genet Dev 2005, 15:270-278.

6. Murray J: Gene/environment causes of cleft lip and/or palate. Clin Genet 2002, 61:248-256.

7. Murray JC, Schutte BC: Cleft palate: players, pathways, and pursuits. J Clin Invest 2004, 113:1676-1678

8. Mossey PA, Little J, Munger RG, Dixon MJ, Shaw WC: Cleft lip and palate. Lancet 2009, 21:1773-1785.

9. Dixon MJ, Marazita ML, Beaty TH, Murray JC: Cleft lip and palate: understanding genetic and environmental influences. Nat Rev Genet 2011, 12:167-178.

10. Zucchero TM, Cooper ME, Maher BS, Daack-Hirsch S, Nepomuceno B, Ribeiro $L$, et al: Interferon regulatory factor 6 (IRF6) gene variants and the risk of isolated cleft lip and palate. N Engl J Med 2004, 351:769-780.

11. Mangold E, Ludwig KU, Nöthen MM: Breakthroughs in the genetics of orofacial clefting. Trends Mol Med 2011, 17(12):725-33.

12. Kondo S, Schutte BC, Richardson RJ, Bjork BC, Knight AS, Watanabe $Y$, et al: Mutations in IRF6 cause Van der Woude and popliteal pterygium syndrome. Nat Genet 2002, 32:285-289.

13. Burdick $A B$, Bixler $D$, Puckett CL: Genetic analysis in families with Van der Woude syndrome. J Craniofac Genet Dev Biol 1985, 5:181-208.

14. Schinzel A, Klausler M: The Van der Woude syndrome (dominantly inherited lip pits and clefts). J Med Genet 1986, 23:291-294.

15. Rizos M, Spyropoulos MN: van der Woude syndrome: a review. Cardinal signs, epidemiology, associated features, differential diagnosis, expressivity, genetic counseling and treatment. Eur J Orthod 2004 26:17Y24.

16. de Lima RL, Hoper SA, Ghassibe M, Cooper ME, Rorick NK, Kondo S, et al Prevalence and nonrandom distribution of exonic mutations in interferon regulatory factor 6 in 307 families with Van der Woude syndrome and 37 families with popliteal pterygium syndrome. Genet Med 2009, 11(4):241-247.

17. Blanton SH, Cortez A, Stal S, Mulliken JB, Finnell RH, Hecht JT: Variation in IRF6 contributes to nonsyndromic cleft lip and palate. Am J Med Genet A 2005, 137A:259-262

18. Ghassibe M, Bayet B, Revencu N, Verellen-Dumoulin C, Gillerot $Y$, Vanwijck R, Vikkula M: Interferon regulatory factor-6: a gene predisposing to isolated cleft lip with or without cleft palate in the Belgian population. Eur J Hum Genet 2005, 13:1239-42

19. Scapoli L, Palmieri A, Martinelli M, Pezzetti F, Carinci P, Tognon M, Carinci F: Strong evidence of linkage disequilibrium between polymorphisms at the IRF6 locus and nonsyndromic cleft lip with or without cleft palate, in an Italian population. A J Hum Genet 2005, 76:180-183.

20. Srichomthong $C$, Siriwan $P$, Shotelersuk V: Significant association between IRF6 820G>A and nonsyndromic cleft lip with or without cleft palate in the Thai population. J Med Genet 2005, 42:e46.

21. Park JW, Mclntosh I, Hetmanski JB, Jabs EW, Vander Kolk CA, Wu-Chou YH, et al: Association between IRF6 and nonsyndromic cleft lip with or without cleft palate in four populations. Genet Med 2007, 9:219-27.

22. Vieira AR, Cooper ME, Marazita ML, Orioli IM, Castilla EE: Interferon regulatory factor 6 (IRF6) is associated with oral-facial cleft in individuals that originate in South America. A J Med Genet A 2007, 143:2075-78.

23. Jugessur A, Rahimov F, Lie RT, Wilcox AJ, Gjessing HK, Nilsen RM, Nguyen $\Pi$, Murray JC: Genetic variants in IRF6 and the risk of facial clefts: singlemarker and haplotype-based analyses in a population-based casecontrol study of facial clefts in Norway. Genet Epidemiol 2008, 32:413-24.

24. Tan EC, Lim EC, Yap SH, Lee ST, Cheng J, Por YC, Yeow V: Identification of IRF6 gene variants in three families with Van der Woude syndrome. Int J Mol Med 2008, 21(6):747-51.

25. Osoegawa K, Vessere GM, Utami KH, Mansilla MA, Johnson MK, Riley BM, et al: Identification of novel candidate genes associated with cleft lip and palate using array comparative genomic hybridization. J Med Genet 2008, 45:81-6.

26. Salahshourifar I, Halim AS, Sulaiman WA, Ariffin R, Naili Muhamad Nor N, Zilfalil BA: De novo interstitial deletion of 1q32.2-q32.3 including the entire IRF6 gene in a patient with oral cleft and other dysmorphic Features. Cytogenet Genome Res 2011, 134(2):83-7.

27. Desmyter L, Ghassibe M, Revencu N, Boute O, Lees M, François G, et al: IRF6 screening of syndromic and a priori non-syndromic cleft lip and palate patients: identification of a new type of minor VWS Sign. Mol Syndromol 2010, 1(2):67-74

28. Jehee FS, Burin BA, Rocha KM, Zechi-Ceide R, Bueno DF, Brito L, et al: Novel mutations in IRF6 in nonsyndromic cleft lip with or without cleft palate: When should IRF6 mutational screening be done? Am J Med Genet A 2009, 149A:1319-1322.

29. Jugessur $A$, Farlie $P G$, Kilpatricj $N$ : The genetics of isolated orofacial clefts: from genotypes to subphenotypes. Oral Dis 2009, 15:437-453.

30. Rutledge $\mathrm{KD}$, Barger C, Grant JH, Robin NH: IRF6 mutations in mixed isolated familial clefting. Am J Med Genet A 2010, 152A:3107-3109.

31. Salahshourifar I, Wan Sulaiman WA, Zilfalil BA, Halim AS: Mutation screening of IRF6 among families with non-syndromic oral clefts and identification of two novel variants: Review of the literature. Eur J Med Genet 2012, 55(6-7):389-93

32. Huang JJ, Hou JW, Tan YC, Chen KT, Lo LJ, Chen YR: Van der Woude Syndrome: Clinical Presentation in 64 Patients. Cleft Palate Craniofac J 2007, 44(6):649-52.

33. Meng L, Bian Z, Torensma R, von den Hoff JW: Biological Mechanisms in Palatogenesis and Cleft Palate. J Dent Res 2009, 88(1):22-33.

34. Wu T, Liang KY, Hetmanski JB, Ruczinski I, Fallin MD, Ingersoll RG, et al: Evidence of gene-environment interaction for the IRF6 gene and maternal multivitamin supplementation in controlling the risk of cleft lip with/without cleft palate. Hum Genet 2010, 128(4):401-410.

doi:10.1186/1471-2350-14-37

Cite this article as: Wu-Chou et al: A combined targeted mutation analysis of IRF6 gene would be useful in the first screening of oral facial clefts. BMC Medical Genetics 2013 14:37.

\section{Submit your next manuscript to BioMed Central and take full advantage of:}

- Convenient online submission

- Thorough peer review

- No space constraints or color figure charges

- Immediate publication on acceptance

- Inclusion in PubMed, CAS, Scopus and Google Scholar

- Research which is freely available for redistribution 